\title{
Theoretical Basics of the Transpositional Grammar of Russian Language
}

\author{
Victor Vasilievich Shigurov (Corresponding author) \\ Ogarev Mordovia State University, Russian Federation \\ E-mail: shigurov591794@mail.ru \\ Tatyana Alexeevna Shigurova \\ Ogarev Mordovia State University, Russian Federation
}

Received: 17-04-2016

Published: 01-09-2016
Accepted: 27-06-2016

doi:10.7575/aiac.ijalel.v.5n.5p.237
Advance Access Published: July 2016

URL: http://dx.doi.org/10.7575/aiac.ijalel.v.5n.5p.237

\begin{abstract}
The article presents the theoretical basics of the transpositional grammar of the Russian language (as the special areas of the functional grammar), which serves as a mechanism for describing the subject of the transposition of the linguistic units from one class (or interclass semantic-syntactic category) to another (or others). The relation to the transposition of the grammar and vocabulary (word-formation) was displayed; a typology of the transpositional processes in grammatical structure of the Russian language was submitted, and above all, in the parts of the speech and inter part-ofspeech classes, grammatical categories and lexical-grammatical classes; general and specific objectives of the study types of transposition of the linguistic units were defined; the fragments of the description of the transition and syncretism of the language units were offered using the technique of opposition analysis and indexation. The results can be used in the development of the theory of the transpositional grammar of the Russian language.
\end{abstract}

Keywords: the Russian language, transpositional grammar, theoretical basics, part of speech, inter part-of-speech class, syncretism

\section{Introduction}

One of the current problems of the modern linguistics is the creation of the transpositional grammar of the Russian language (as a special branch of the functional grammar), where the nature and purpose of the mechanism of the transposition in the Russian language will be studied; relation to the grammar and vocabulary will be shown; a typology of the transpositional processes in the field of the part-of-speech and inter part-of-speech syntactic-semantic classes, as well as the grammatical categories and lexica-grammatical types will be developed; the types of the functional and functional-semantic homonyms will be identified and characterized, as well as the syncretic entities, representing different stages of the transition of words and phrases from one part of speech to another; heterogeneous speech patterns will be described, using the methods of the mathematical processing of the material, the indices of the different levels (degrees) part-of-speech transposition of the lexical units caught in the zone of influence (interaction) of three or more classes of words with the "inclusion" into several transpositional processes, among which is the one of the dominant type of transposition (e.g. interactivation) and some accompanying parallel processes (verbalization, predicativization, pronominalization, particulation, etc.) will be calculated. Extremely important is the study of character of the interaction of vocabulary, word formation, and morphological and syntax factors in the process of the categorical transformation of the linguistic units.

\section{Methods}

The methods of the oppositional analysis and the indexation of the various facts of syncretism in the system of the partof-speech and inter part-of-speech syntactic-semantic classes stated and tested in a series of monographs by V.V. Shigurov on transpositional grammar of the Russian language. Stages (1) of substantivization, adjectivization, adverbialization, conjuctionalization of the participial negative forms of the verb have been researched (Shigurov 1993); (2) stages of pronominalization of the language units of the different parts of the speech (Shigurov 2003); (3) stages of interactivation of the language units of the different parts of speech and its companion transpositional processes of verbalization, particulation, etc. (Shigurov 2009a); (4) stages of predicativization and its companion processes of adjectivization, adverbialization, modulation etc. (Shigurov 2009b). The catalogue of the transpositional grammar of the Russian language has been composed and the research program of the transpositional process in grammatical system of the Russian language has been developed.

\section{Results and discussion}

The main trends of the research in the transpositional grammar include: 
- The types of the transpositional processes at the part-of-speech level (substantivization, adjectivization, adverbialization, pronominalization, numeralization, prepositionalization, conjuctionalization, particulation, interactivation) and semantic-syntactic part-of-speech digits (predicativization, modulation); types of the functional and functional-semantic homonymy in the system of the grammatical word classes; the step character of the transformation of the word forms, causing the occurrence of syncretic, i. e. peripheral and intermediate, hybrid formations in the structure which combines differential features of different classes; the graphical explication of the steps of transposition of the linguistic units in the form of the transition scale developed by V.V. Babaytseva (2000); negation as the factor, providing limiting and modifying effect on the implementation of the categorical attributes of parts of speech, as well as conditioning (or accompanying) their transposition into other classes, due to the asymmetrization of the linguistic symbols (Shigurov, 1993);

- Types of the transpositional processes at the level of grammatical categories (type, voice, mood, time, person, gender, number, degrees of comparison);

- Types of transpositional processes at the level of the lexical-grammatical categories (nouns: proper / common; animate / inanimate; concrete / abstract / material / collective; adjectives: qualitative, relative, possessive; Verbs: action class : general effective / evolutionary / stative / inchoate, etc.; transitive / intransitive; personal / impersonal, and others);

- Types of the transposition processes at the level of the syntax (the sentence and the syntactic structures).

The dominant feature in the transpositional grammar of the Russian language is the concept of transposition manifested one of the active mechanisms of the language: translation of the mark (word forms, words, and words' combination) from one category (class) into the other. The essence of the transposition is to change the properties of the linguistic unit, its combinatorics and proportions, that is the loss of its differential features, relatively speaking, the initial part of speech and the acquisition of the differential features of other derivative parts of speech (or several with multi-faceted cooperation of several part-of -speech and inter part-of-speech classes $-3,4$ or more - in the structure of one unit); see. e.g. research by Sh. Bally (1955, pp. 130-143), V.N. Migirina (1971, pp. 131-147), V.V. Babaytseva (2000), M. Kim (1978), E.P. Kalechits (1990); M.F. Lukin (1973), A.J. Bauder (1988, p. 13-19), V.V Shigurova (1988; 1993; 2003; 2009a; 2009b); I.V. Vysotsky (2006) and others. Many aspects of the mutual transition and interaction of the language units in the framework of the transposition theory (translation, conversion) have been discussed in the works of foreign researchers; See. e.g. (Bally, 1955; Tener, 1988; Kurilovich, 2000; Marchand, 1967; and others).

Under the categorical transformation the language unit transposes (relatively speaking, it moves) from one semanticgrammatical category into the other, explicating in the typical contexts some degree of approximation to a new part of the speech (or inter part-of-speech category). The steps (stages and substages) of the part-of-speech transposition of words and phrases can be set by the opposition analysis and indexation. The different types of the multi-transposition of words and phrases from one class to another (both single and combined in one single lexical unit) generate grammatical and lexica-grammatical homonyms as well as the syncretic speech formation which combine the properties of the structure of the several parts of speech - two, three, four, etc., see e.g. (Shigurov, 1988; 1993; 2003; 2009a; 2009b; Shigurov, \& Shigurova, 2014; Shigurov, \& Shigurova, 2015). Such hybrids allow to transfer in a saving manner semantically capacious human thoughts and feelings in all their diversity and natural interaction (Babaytseva, 2000, p. 179, et al.).

It is important to emphasize that the term "transposition" is of purely synchronous (not diachronic!) interpretation. It is used sometimes as an absolute synonym for the terms "transformation", "movement from one part of speech to the other," when it comes to the process and in the result of changes of the differential features in the structure of the language units located in the different contexts in the area of attraction (interaction) of several parts of speech.

At the same time, a certain combinatorics and proportion of the part-of-speech features in the word form, subject to one or more types of the categorical transpositions, reflect the characteristics that emerged as a result of prolonged use in speech (which is, of course, the scope of diachrony). However, these features are fixed on a synchronous cut in the typical context of the transition. The concepts of "transposition", "transformation", "transition ..." are generic terms with respect to the relevant specific concepts such as "substantivization", "adverbialization", "pronominalization", "interactivation" explicating the specific kinds of transposition in the system of part-of-speech and inter part-of-speech categories of the Russian language (many of these terms are fixed by Shakhmatov, 1941, pp. 454, 499, 502, etc.).

A comprehensive study of all types of the transpositional processes at the different language levels involve resolution of both general and specific problems. Among the common challenges in the area of part-of-speech transposition it is important to note the following:

- Determination of the nature and purpose of the mechanism of transposition of the linguistic units at the level of the word classes and the interclass syntactic-semantic categories (predicatives, parenthesis-modal words);

- Registration of all types of the linguistic units' movement in the part-of-speech and inter part-of-speech classes;

- Characteristics of the emigration and immigration transposition (transformation) (term of V.N. Migirin) of the language units in the context for each part-of-speech and inter part-of-speech category; 
- Identification of the linguistic and extra-linguistic reasons of possibility / inability of the certain types of the part-of-speech transposition of language units;

- Analysis of the transpositional processes in the field of part-of-speech and inter part-of-speech classes in the aspect of their one-sidedness / versatility, single-stage / multistage, reversibility / irreversibility, and so on.

- The classification of the part-of-speech and inter part-of-speech classes (predicatives, parenthesis-modal words) with respect to the theory of the transpositional (transition) processes;

- The explanation of the history of the occurrence (genesis) of part-of-speech and inter part-of-speech classes in light of the study on transposition, and others.

The study of the specific aspects of the stepped transposition of the linguistic units in the part-of-speech and inter partof-speech syntactic-semantic classes based on the methodology of the opposition analysis and the indexation of separate stages of transposition (adjectivization, pronominalization, adverbialization, predicativization, modulation, particulation, interactivization, etc.) suggests the solution of particular objectives. The most significant objectives are as follows:

- Identifying semantic, morphological preconditions and syntactic conditions of the categorical transformation of the language units;

The definition of the form (fast /slow) and the features of the transition of words and phrases from one part-of-speech / inter part-of-speech class into the other part-of-speech / inter part-of-speech class or to the several part-of-speech / inter part-of-speech classes - when they interact within intersecting transpositional processes (changes at the level of the lexical and general grammatical semantics, grammatical categories and paradigms, syntactic functions, lexical and syntactic distribution, morphemic structure and word-building opportunities, phonetic characteristics, etc.).

The multi-aspect semantic-grammatical characteristic of the words and word forms, subject to the categorical regeneration under adjectivation, adverbialization, predicativization, modulation, etc. in a varying degree (semantics, morphology, syntax);

- The establishment of the steps (stages) of the part-of-speech transposition of the linguistic units, presented in the standard contexts, on the one hand, the typical (nuclear) events, having all of the distinctive features of the relevant parts of speech $(\mathbf{A}, \mathbf{B})$ and on the other hand - syncretic structures, in different proportions combining the properties of the original and derivative parts of speech $(\mathbf{A b}, \mathbf{a b}, \mathbf{a B})$;

- The development of the criteria for distinguishing grammatical and lexical-grammatical homonyms and syncretic (peripheral and hybrid) formations, synthesizing in equal proportions the signs of the initial and final links of the part-of-speech transposition;

- The calculation of the facts of the multi-aspect interaction of more than two part-of-speech and inner part-ofspeech classes in the structure of the language units at the intersection of several transpositional processes; identification of combinatorics and proportions of the distinctive features in sincretes at the different stages of their simultaneous adverbialization, predicativization, interactivation, etc.

- Drawing up a complete list of the units, in one way or another affected by the transpositional processes at the level of the part-of-speech and inner part-of-speech classes.

The most important task of the transpositional grammar is to study the mechanism and the principles of the lexical and grammatical interaction in the structure of the language units, exposed to the transpositional processes in the part-ofspeech system and inner part-of-speech classes. "The grammatical and lexical forms are organically bound - wrote V.V. Vinogradov - and constantly influence each other. Therefore, the study of the grammatical structure of the language without its lexical side, without taking into account the interaction of the lexical and grammatical values is impossible" (Vinogradov, 1986, pp. 16). Especially clearly this interaction becomes apparent under the functioning of parts of speech, their grammatical categories and lexical-grammatical classes.

The result of this cooperation is the facts of transition and syncretism, for example, in the area of the lexical and grammatical word classes. It is well known that one noun, depending on the lexical semantics is able to present various lexical and grammatical classes (e.g. teaching - abstract or collective), while another in the same lexical meaning may belong directly to the two subclasses at the same time (e.g. raspberries, strawberries - material and collective subclasses).

Thus in some cases, vocabulary and grammar operate synchronously in the word form [brother is an animate noun representing a living human being, human (by lexis) and have similar forms in the accusative and genitive cases, single and plural numbers; compare: Ya vizhu brata and Net brata (grammar)]. In other cases belonging to the category can only be defined taking into account the semantic criteria. For example, we can prove that the word studentship is an animate noun, only taking into account its semantics (the 'totality of living creatures, the students'), and grammatically it is not possible to prove: an abstract noun of the neuter gender has no plural form, where you could find the paradigmatic figure of an animate object.

Finally, there are some cases where the same noun, being a syncretic noun, can be incorporated directly into two lexical and grammatical categories: with the view of the word semantics - to one category, and with the view of its grammar to another category [jump: abstract (lexis: 'process') + specific (grammar: jumping, two jumps, etc.)]. 
Of the fundamental importance is the demarcation of two types of transposition of the linguistic units in the part-ofspeech and inter part-of-speech classes - functional-semantic (or semantic, Sh. Bally's terminology) and functional types. Functional-semantic transposition, being the fact of grammar and vocabulary, includes the change both in the grammatical features and lexical-semantic features of the words and word forms being exposed to a categorical (part-ofspeech) transformation. As a result the linguistic units become categorically "bifurcate" and "spin-off" from them, these word forms (twins) turn into a new class; compare: Podkhodiashchiy $k$ stantsii poezd zamedlil khod (imperfect participle from the verb to approach) -> On iskal podkhodyashchiy moment, chtoby soobshchit' etu novost' (participle pronoun) (see [Shigurov, 1993, 2003]). The functional transposition, in contrast, has no relation to the word formation, presenting a purely grammatical process associated with the part-of-speech (categorical) attributes of the word forms.

The nature of the functional transposition of the linguistic signs is exceptionally complex. Without going into the history of the issue, we note that within its boundaries the two types can be distinguished: 1) the transition of the language units from the different parts of speech into particular inter part-of-speech semantic-syntactic categories of words - predicatives and modal-parenthesis words (Brief Russian grammar, 1989, pp. 22-23, 302, etc.), and 2) a purely grammatical transition of words and phrases from one part of speech into the other (substantivization, adjectivization, adverbialization, etc.), not violating the identity of the original lexeme.

The first type of the functional (grammatical) word forms transposition in the part-of-speech system is known in the Russian grammar as "predicativization" and "modulation". We understand regard predicativization as the use of the word forms included in the classes of the nouns, adjectives, pronouns, adverbs, verbs in the form of short passive participles (go, sad, cold, nothing, ventilated, forbidden), in a particular function of the principal term (predicate) of the impersonal construction for transfer of semantics of the state and / or its evaluation. Compare the following functional homonyms:

(1) (a) Delo plokho (short adjective);

(b) On plokho ponimaet po-russki (adverb);

(c) Yemu plokho (short adjective / adverb in a predicative function);

(2) (a) Idyot okhota na volkov (noun);

(b) Okhota otdokhnut' (noun in a predicate function).

The modulation process presents the usage of the word forms, related to the class of nouns, adjectives, verbs, adverbs (right, fact, it is obvious, it seems, most importantly, to be seen, of course, they say, look, you know, and so on.) in a special parenthetical function for the expression of the subjective-modal semantics, that is the relationship of the speech subject to what he /she reports. The viewpoint of the modus subject manifests the different aspects of the characteristics of the statements: (1) confidence / lack of confidence in the reality of the transmitted events (positively, for sure, of course, obviously, probably, it seems, etc.); (2) the emotional attitude to the reported (luckily, unfortunately, etc.); (3) fixation of the progress of the presented ideas (first, therefore, that means, etc.); (4) a method of formation of thoughts (in short, short, etc.); (5) the call to the other party in order to draw his/her attention to anything (you see, you know, can you imagine, I'm sorry, let's say, for example, supposably, etc. (6) a reference to the source of information (in my opinion, to be heard, etc.) (Vinogradov, 1986, pp. 603-607). Compare the following functional homonyms:

(3) (a) Privedennoye nastroyeniye kazhetsya vo mnogom iskusstvennym;

(b) Pogoda, kazhetsya, okonchatel'no isportilas';

(4) (a) Eto pokhozhe na pravdu.

(b) Pokhozhe, bez postoronney pomoshchy vam ne oboytis';

(5) (a) Izdaniye knigi vpolne vozmozhno;

(b) Vozmozhno, kniga budet skoro izdana;

(6) (a) Ukazanniy fakt zasluzhivaet vnimaniya;

(b) On ne pridyot, fakt.

Note also the loss (or neutralization) of the semantic and grammatical properties of the adjective in the adjective word form seen in the contexts of predicativization and modulation: 1. Otsyuda plokho vidno rechku (adjective word form as the function of the estimated modal predicative) and 2. Vidno, my oshchiblis' (adjective word form as the function of the estimated modal component).

Small groups of lexical items not having the homonymous correspondences among the significant and ancillary parts of speech in the modern Russian language, are functionally approaching the predicatives and input modal words arisen as the result of predicativization and modulation words and word forms of different parts of speech. For example, such impersonal-predicative form like it is necessary, it is possible, must not, sorry, shame, ashamed, ticklish, sickening, unbearable, could not stand, unaware and input modal words like so, therefore, for example, firstly, secondly, thirdly, it seems, however, that sometimes jokingly referred to by the linguists as part-of-speech "bums" or "rootless" words.

See, for example, usage of these "homeless" words in parenthesis and modal contexts:

(7) Po-vidimomu, skoro budet dozhd';

(8) Navernoye, pora sobirat'sya v dorogu. 
The second type of functional transposition in the part-of-speech system of the Russian language is represented by numerous cases of categorical grammatical transformation of the word forms within the framework of adjectivization, adverbialization, substantivization, pronominalization, etc. These are basically two processes: 1) the regular grammatical generation of one part of speech within the boundaries of the corresponding lexical items of the other part of speech and 2) an occasional (speech) part-of-speech transposition of word forms. An example of a typical generation of a new part of speech within the original lexical items can be, for example, the facts of the two-stage functional transposition of the verb into an adjective and an adverb, that can explain the orientation of participles and gerunds to the "part-of-speech emancipation" (an expression of Rudelev, 1996, pp. 85-86).

As a result of the first stage of the grammatical transposition of the verb into the adjective different morphological types of participles can be formed (chitat' --> chitaushchiy, chitavshiy, chitaemiy, chitanniy, chitayushchiysya, chitavshiysya), as a result of the second stage the functional participial adjectives can be formed (ranenniy v boyu soldat --> raneniy soldat; krashenniy malyarom zabor --> krasheniy zabor; plavayushchiye vdaleke utki --> plavayushchiye tanki; shagayushchiy na platsu soldat --> shagayushchiy ekskavator; slova, izmenyaemiye po kategoriyam padezha, roda $i$ chisla --> izmenyaemiye slova, etc. (Bulanin, 1986, pp. 36-38; Shigurov, 1993, pp. 246-249, 303-305). The adverbial verb transposition also includes two stages: firstly, it is the formation of adverbial participles (chitat' --> chitaya, prosmotret' --> prosmotrev) and secondly, the formation of functional adverbs that are formed of adverbial participles: On govoril, izredka ulybayas' --> On govoril ulybayas', i.e. s ulybkoy; see also: idti spotykayas', shatayas'; govorit' zaikayas'; sidet' sgorbivshis', and some other examples).

It is important to emphasize that the adjectival and adverbial verb transposition, accompanied by certain grammatical and semantic shifts, does not lead to violation of the identity of the original lexical item. This means, for example, that in such cases as raneniy soldat (solyonaya ryba, zhareniy kartofel', kvashenaya kapusta, krasheniye steny) and govorit' ulybayas' (idti spotykayas') we are dealing with the participial adjective raneniy and the adverb ulybayas', formed out of the adverbial participle, functioning under the relevant verbal lexical items ranit' and ulybat'sa. This is a purely grammatical process without affecting the sphere of word formation. Lexicalization of grammatical forms does not occur in such cases. In view of the above, the practice of the orthographic differentiation of imperfective participles and functional participial adjectives such as potatoes zharenniy na sale kartofel' - zhareniy kartofel', kipyachennaya $v$ chaynike voda - kipyachenaya voda), can be hardly considered as successful and linguistically-justified, the more especially as such differentiation still cannot be implemented; for example, marinovanniye khozyaykoy griby (passive participle) - marinovanniye griby (participial functional adjective).

The situation gets more complicated by the fact that perfective passive participles and functional adjectives appeared on their base, do not have such orthographic difference; for example, izbalovannaya mater'yu doch (passive participle) izbalovanaya doch (participial adjective).

For comparison, the functional-semantic transposition of verbal word forms into an adjective and an adverb (more specifically, adjectivization of participles and adverbialization of adverbial participles) is accompanied by a loss of not only grammatical features, but also lexical meaning of the verb. For example: nachitanniye lektsii --> nachitanniye lyudi; On govoril dolgo, ne toropyas' obobshchat' --> On govoril ne toropyas'; see also: otvechat' nekhotya; zvonit' nemedlya; zrya otkazat'sya), etc.

The contexts illustrating the facts of functional and functional-semantic transposition of participles into adjectives, are also demonstrative: 1) mytyye khozyaykoy frukty (participle) --> mytyye frukty (participial adjectives denoting a new, secondary quality chistyye and functioning within the initial verbal lexical item $m y t^{\prime}$ as its special adjectival type of use) and 2) sobranniy masterom priyomnik (participle) -> sobranniy chelovek (participial adjective, which goes beyond the scope of the original semantic verb sobrat' and used as a separate lexical item). In the first case we are dealing only with the fact of grammar [compare grammatical homonyms mytyye (participle) - mytyye (adjective)], while in the second case - we are dealing with the fact of grammar and vocabulary [compare grammatical and lexical homonyms: sobranniy (participle) - sobranniy (adjective)]. In case of functional adjectivization participles lose their grammatical verbal characteristics, but retain the identity with the original lexical item, while in case of functional-semantic adjectivization they lose both grammatical verbal properties and their lexical semantics. Compare also initial and final links of functional-semantic transposition of the verbal imperative into the form-generating particle: Let students come in the class by turn (Puskay po ocheredi uchenikov v klass --> Puskay reshayut, ne meshayte im.

We can observe the facts of functional and functional-semantic transposition in case of impersonal-predicative transposition of linguistic units of different parts of speech. Thus, in summary predicativizated short passive participles ending in -no, -to, the degree of semantic deviation from the verbal lexical items can be different - the degree can be lesser (in case of predictivization and/or adjectivization; for example: Uzhe poslano $v$ pogonyu; Ob etom napisano $v$ gazete "Komsomol'skaya pravda"); $V$ komnate ubrano $i$ provetreno; or greater [in case of functional-semantic predicativization; Im razresheno ostat'sya ( $\approx$ 'can'); V etom meste kurit' zapreshcheno ( $\approx$ 'You cannot smoke here'); Nam prishlos' atakovat' ( $\approx$ We were 'forced' to attack)]. The semantic shift in predicativizated linguistic units representing different parts of speech (it's time to/for (pora, vremya, dosug), early (rano), late (pozdno), dare you...? (slabo), stand at ease (vol'no); ordered (veleno), etc.) is connected with the formation of a modal component in their semantic structure.

Homonymous collision of word forms due to the predicativization of nouns and short adjectives / adverbs ending in - $o$, can be illustrated by typical contexts: 
A. Grammatical homonyms: Len', son i pokoy - vsyo eto sposobstvuyet entropii, raspadu, nashemu perekhodu v pyl'. (Dudincev V. White clothes) (this noun means 'Lack of desire to do anything') --> Yey is mesta-to len' podnyat'sya (Tokareva V. Love and travel) (this substantival predicate means 'reluctance'); I v samom dele, eto bylo krasivo $i$ vpechatlyaushche (Voinovich V. Monumental propaganda) (short adjective); Ekspozitsiya byla postroena logichno $i$ krasivo (Dovlatov S., Natural reserve) (adverb) --> A zdes' bylo krasivo... - zapushchennost' byla k litsu etomu mestu (Ulitskaja L., Travel to the seventh part of the world) (an estimated predicate on the basis of a short adjective and adverb).

B. Lexical and grammatical homonyms: A potom - izvestnoye delo: sadilis', i kazhdiy po-svoyemu ubival svoy dosug... (Yerofeyev M., Moscow-Petushki) (the noun means 'spare time') --> Dosug mne razbirat' viny tvoi, shchenok (Krylov I.A.) (this substantivisated predicate means "I cannot as I have no time, and does not want to do that); ... Zdes', vetikh starykh, iznoshennykh izbakh, kak $v$ derevne, lozhat'sya rano (Rasputin V.G.. A new profession) (adverb) --> Rano eshchyo emu poruchat' takiye dela: ne spravitsya (adverbial predicate meaning "He must not deal with such deeds as he is not ready for that").

Purely functional transposition of the verb into a noun is a single-stage one, being associated with the formation of the grammatical form of the infinitive: Chitat' lyozha vredno. However, further movement of the verbal word towards the noun becomes functional-semantic in nature and results in the formation of substantivates like russkaya pech' (<-pech' bliny); vsya znat' goroda (<-- khorosho znat' predmet razgovora), etc.

Occasional transition of a word form from one part of speech to another as a kind of functional transposition is a very common phenomenon in the Russian language. It is found in virtually all types of part-of-speech transformation and, being designed for a particular case, is always temporary, transient in nature, symbolizing one or another stage of transition of a word form from one class to another. See, for example, speech adverbialization of case and prepositionalcase forms of nouns (9-10) and speech substantivization of word forms of different parts of speech (11-12):

(9) Zver' ranen streloy.

--> Molniya streloy pronzila nebo;

(10) On s bol'shym trepetom ozhidal yeyo poyavleniya

--> On s trepetom ozhidal yeyo poyavleniya

(11) Vsyakoye beloye markoye, markoye khot' i neudobno, no krasivo;

(12) Resheniye neobkhodimo prinimat' zavtra.

--> Nashe zavtra neopredelenno.

Cases of functional substantivization of verbal symbols (metasubstantivization) can be rather demonstrative:

(13) Rassmotreli vse "za" $i$ "protiv".

It should be noted that the contextual transposition of word forms of this type into an unusual position of a subject and complement can only be syntactical in nature and thus it limits their transformation. Therefore there can be doubts about the fair use of the term "substantivization" to describe these facts (Bauder, 1988, p. 15).

The facts of usual adverbialization of adverbial participles and short neuter singular adjectives represent a special case of functional transposition of word forms.

(14) Khudozhnik risuyet, stoya na podmostkakh

--> Khudozhnik risuyet stoya;

(15) Litso yego bylo veselo --> On veselo ulybalsya.

In the modern literature on word-formation the adverbs like veselo are often interpreted as a syntactical adjective derivatives preserving lexical meaning of the original words (such cases as begat' --> beg, smeliy --> smelost', kamen' -> kamenniy), as indicated in the works of Kurilovich E. (1962, 57-70)

As it has been said before, transposition processes of the mentioned type have a stepped character, generating in the speech a mass of syncretic phenomena combining the features of initial and derivative part of speech (or inter-part-ofspeech type) in different proportions. The study of these types of syncretism is one of the greatest challenges of modern linguistics. As Babaytseva V.V. pointed out, "typical speech facts ("extreme cases", in the words of Schebra L.) easily fit into the columns ("cells") of different classifications, and, as a rule, do not raise questions. Another thing is a speech material, that does not fit into the strict framework of even the most detailed classifications. In the living language and speech prevail the facts that do not have a complete set of distinctive features of any single grammatical category (Babaytseva, 2000, pp. 3-4). "The facts of language, - wrote Gak V.G. - form some kind of continuum - a chain of gradual transitions. The last units in the chain are clearly different from each other, but they are related by the area of gradual transitions where it is impossible to draw distinctive lines entirely and permanently" (Gak, 1997, p. 63). The language system appears to be "in a closed chain, where the boundary units linked to each other partly share common elements included in one unit upon some features, and in another, neighboring unit upon different features" (Yartseva, 1968, p. 14).

Generating syncretism of language units in speech may be connected, in particular, with predicativization of words and word forms, leading to "the complex grammatical interweaving" of properties and functions of different parts of speech 
in their structure - nouns, adjectives, numbers, pronouns, verbs and adverbs. The forms of manifestation of this interaction are varied. Thus, in case of predicativization the adjectival forms (zhalko, bol'no, etc.) appear are "in the zone of interests" (attraction) of verbs and adverbs, acquiring, on the one hand, verbal characteristics (semantics of the state, the function of the predicate, impersonality, compatibility with an infinitive, direct transition; for example: zhalko yego, bol'no glotat'), and on the other hand - some adverbial features [invariability, the suffix -o, the meaning of the action attribute (the word form like veselo on the hybridity stage of the predicativization scale, presented in a two-part formation with a prepositional infinitive-subject: Katat'sya s gorki - veselo - semi-adjective/semi-adverb/semipredicate]).

Predicative transposition of an adjectival word form is due to its "inclusion" in two simultaneous transposition processes at the part-of-speech level - verbalization adverbalization. The different degree of convergence of a linguistic unit with verbs and adverbs can be established using the oppositional method and indexation of certain degrees and the limit of its predicativization (Shigurov, 2009a; 2009b).

The situation is complicated by the fact that a predicativizated adjectival word form often appears in the zone of attraction of not only adjectives, verbs and adverbs, but other classes of words such as pronouns with the semantics of indefinite plurality (like neskol'ko and imperative-emotive interjections.

Compare different types of transposition of a word form dostatochno:

(16) Etikh knig dostatochno (i.e. so much as necessary, the number corresponds to a certain situational norm: adverbialization and pronominalization - pronoun-numeral type of using an adverbialized adjectival word form);

(17) Inogda dostatochno vzglyanut' na cheloveka, chtoby ponyat', kto on [rapprochement with the verbs and adverbs in the framework of predicativization (quantitative assessment of the action in the infinitive), as well as with indefinite pronouns in case of pronominalization]. In the modern academic dictionaries (Dictionary of the Russian language in 1981, Vol. 1: 436), using a word form dostatochno within the meaning of the word form "stoit tol'ko (sdelat' chto-libo)") is associated with an infinitive and conjunction chtoby. It is thought that the scope of its using is somewhat broader. It should be borne in mind that, instead of the infinitive, here we can use a verbal noun; for example: Inogda dostatochno odnogo vzglyada na..., chtoby ponyat'. The conjuction chtoby may be absent, for example, in the conjuctionless construction: Inogda dostatochno vzglyanut' na ... $i$ situatsiya stanovitsya yasnoy. Furthermore, there is not always an indication to the action target in the sentence, although this information can be extracted from the broader context or presented at the presupposition level: Ikh ne nado zapugivat', dostatochno perekryt' im dostup $k$ informatsii (in case of possible implication of the meaning "not to do any harm").

(18) Dostatochno plakat', skol'ko mozhno! Perestan'te! [interjectivization (emotional appeal to stop the action), verbalization, predicativization, pronominalization].

Word-forms ne dostatochno, malo are subject to two types of transposition with a combination with the adjacent postpositional infinitive:

(19) Malo ponyat', nado deystvovat' (predicativization + pronominalization).

Functioning of the word form Gor'ko! should be noted (this is a phrase that guests outcry at the wedding table, urging newlyweds to kiss and thus, upon the tradition, to remove the feeling of bitterness in the mouth after drinking wine, champagne, etc.) in the syncretism context of interjectivization, verbalization and predicativization.

"Pure" (20) and "combined" (21) types of predicativization can be presented by word forms kholodno, zharko, bol'no, plokho, etc.

(20) Yетu kholodno (predicative with semantics of the physical condition of the subject; predicativization);

(21) Mne kholodno! Ty ne slyshysh'?! (the phrase accompanied by an imperative intonation cam imply the meaning "Zakroy dver', okno!"); the context of the combined predicativization, interjectivization and verbalization).

Similarly:

(22) V komnate zharko (predicativization);

(23) Mne zharko! (At the presupposition level it can mean: "Open the window for me to feel better", this is the context of the combined predicativization, interjectivization and verbalization).

As for part-of-speech context, the following inscription is rather interesting: Opasno: Tigry! [The context of combined predicativization (negative assessment of the situation with the implication of the emotional state of the subject), verbalization (functional convergence with the imperative verb, compare: Osteregaytes'! Bud'te ostorozhny!, interjectivization (functional convergence with the imperative-emotive interjection; compare: Tss! Karaul!).

It is important to emphasize that in the contexts of this type a linguistic unit is located at the intersection of several transposition process at the part-of-speech level and semantic-syntactic inter-part-of-speech categories (predicatives), i.e. in the "zone of interests" of a number of words classes and categories. Moreover, the degree of its approximation to them is different. Thus, in typical contexts like: Yemu dostatochno bylo nameknut', chtoby vopros byl reshyon, adjectival/adverbial word form dostatochno within the predicativization reached the periphery of predicates bearing infinite-quantitative assessment of the action (in the infinitive), and at the same time we can say that within the pronominalization this word form took one step toward pronouns-numerals and pronouns-adverbs having infinitequantitative meaning; compare: Bylo provedeno neskol'ko opytov; Sleduyet provesti stol'ko opytov, skol'ko nuzhno dlya ob'ektivatsii resul'tatov; Nuzhno stol'ko rabotat', skol'ko trebuetsya). 
The multi-dimensional analysis of the facts of syncretism allows to objectify the results of the study. As pointed out by Kuznetsova A.I., "the same phenomenon from different points of view can be described as both central and peripheral" (Kuznetsova, 1985: 16). It should be added that in some cases it is possible to indentify the same fact as a hybrid fact, i.e. synthesizing in its structure the signs of the other interacting word classes in equal proportion. Practically, this means that the same speech fact can be qualified from three perspectives: a) as a central (nuclear) phenomenon; b) as a peripheral phenomenon; c) as a hybrid phenomenon. Everything depends on the coordinate system in which we assess this speech fact. It can be illustrated by the mentioned word form dostatochno. As for its predicativization, we can qualify it as a functional peripheral predicate that has not lost its semantic link with the original generating lexical item - an adjective in a short form (Resheniye dostatochno dlya ...) or an adverb (dostatochno smeloye zayavleniye), but if we are interested in the degree of pronominalization of this word form in the above-mentioned context of transition, thus, it is possible to ascertain its rapprochement with many words of different parts of speech such as mnogo, malo, navalom, tucha, polno, zavalis', khvatit, that takes the first step toward an pronouns meaning indefinite variety (Compare: Yagod navalom, polno, zavalis' (Shigurov, 2003).

It is obvious that the degree of convergence of predicativated words and phrases with verbs, adverbs, adjectives, nouns and pronouns in different conditions of the context is not the same, as indicated by the different stages of their predicativization, pronominalization, etc., requiring quantitative measurement by the formula of part-of-speech compliance (indexation).

The proposed approach to the material can be illustrated by a model for the description of transitional, syncretic forms, manifesting combined types of part-of-speech transposition of linguistic units in the adverbial system. Observations show that an adverbial word form dostatochno, for example, in the context of transition (Dovol'no! Skol'ko mozhno rasstraivat'sya!) is exposed to three types of transposition - interjectivation, verbalization and pronominalization. Indexation of this speech fact indicates that this is a syncretic formation (relatively - imperative-emotive interjection) Dovol'no, synthesizing properties of the following classes of words in different proportions: adverbs - $17 \%$; interjections $-75 \%$; verbs $-7 \%$; pronouns-numerals $-15 \%$.

Changes in the set and proportion of distinctive features of these parts of speech in the structure of the adverbial word form, undergoing interjectivation, verbalization and pronominalization, occurs in the "movement" of the word form on the scale of transition, which is reflected in the appropriate context: Stage N(arech) (core of the adverb: Eto dovol'no smeloye zayavleniye, pronouns-numerals - 0\%) --> Stage $\mathbf{n}(\mathbf{a r e c h}) \mathbf{m}(\mathbf{m e z h d}) / \mathbf{M}(\mathbf{e z h d})$ (a transition zone between the hybrid adverbial-interjectival formations and the core of interjections - emotive words: Dovol'no rasstraivat'sya!; adverbs - 15\%; interjections - 63\%, verbs - 9\%; pronouns-numerals - 23\%) --> Stage n(arech) M(ezhd) / M(ezhd) (a transition zone between the peripheral, imperative and nuclear emotive interjections: Dovol'no! Skol'ko mozhno rasstraivat'sya!; adverbs $-17 \%$; interjections $-75 \%$, verbs $-7 \%$; pronouns-numerals - 15\%) (you can find details on the application of the indexation method in the study of different types of interjectional transposition of word forms in [Shigurov, 2009a]).

The comparative analysis of the data shows that in the general dynamics of the semantic-grammatical development of the word form dovol'no, engaged in three transposition process, there is a regular decrease in a number of adverbial features in its structure (from 100\% to 15-17\%) and an increase in a number of interjectival features (from 0 to $75 \%$ ). A quantitative indicator of adverbial features of the imperative-emotive interjection Dovol'no is a bit higher (17\%) than this indicator of the interjectival phrase Dovol'no razgovorov! (15\%), due to the syntactic conditions of their use - in combination with dependent words [in case of expanding the valence of a word form on the stage $\mathbf{n}(\operatorname{arech}) \mathbf{M}(\mathbf{e z h d}) /$ $\mathbf{M}(\mathbf{e z h d})$ ] or in a single syntactically isolated position [on the stage $\mathbf{n}(\mathbf{a r e c h}) \mathbf{M}(\mathbf{e z h d}) / \mathbf{M}(\mathbf{e z h d})$ ]. An influence of pronouns-numerals on the interjectival phrase can be seen in the contexts corresponding to the steps $\mathbf{n}(\operatorname{arech}) \mathbf{m}(\mathbf{e z h d}) /$ $\mathbf{M}$ (ezhd) and $\mathbf{n}$ (arech) $\mathbf{M}$ (ezhd) / M(ezhd) of the transition scale. However, as an interjectivated word form to the center of interjections as a part of speech, this influence decreases a little (from $23 \%$ to $15 \%$ ). A similar trend can be observed in the verbalization of the interjectival phrase: the degree of the verbal influence on it decreases from the stage $\mathbf{n}$ (arech) $\mathbf{m}(\mathbf{e z h d}) / \mathbf{M}(\mathbf{e z h d )}$ (9\%) to the stage n(arech) M(ezhd) / M(ezhd) (7\%) of the transition scale.

\section{Conclusion}

Thus, the facts of the interaction of word classes and intra-class semantic-syntactic categories in the structure of language units, subject to one or more categorical transformations, show that the further development of the theory of functional grammar and the field approach, according to some researchers, in particular, Pavlov V.M., should be associated with the study of the facts of transposition and syncretism in the part-of-speech system (Pavlov, 2001, p. 1). The effectiveness of such studies is provided by the systemic use of the method of the oppositional analysis (with the graphic explication of its results on the intersecting scales of intra-category transposition of language units) and mathematical methods of processing of the empirical material - indexation of different degrees of compliance of the syncrete with initial and final links of transposition. It should also be taken into account that the processes of part-ofspeech transposition and word formation are closely interact with each other and often intersect in the structure of language units at different stages of their categorical degeneration (Zernov, 1986, pp. 10-11).

\section{Acknowledgements}

The work has been performed as part of the project "Complex research of modulation as a type of stepwise transposition of linguistic units into the semantic-syntactic category of parenthesis-modal words" implemented with the financial support of the Russian Humanitarian Science Foundation (grant number 15-04-00039a). 


\section{References}

Babaytseva, V. (2000). Phenomena of transition in the Russian grammar: monograph. Moscow: Bustard.

Bally, Sh. (1955). Total linguistics and issues of the French language. Moscow: Foreign Literature Publishing House.

Bauder, A. (1982). Parts of speech - structural and semantic classes of words in modern Russian. Tallinn: Valgus.

Bauder, A. (1988). Phenomena of transition in the grammatical structure of modern Russian language and related phenomena. The phenomena of transition in the grammatical structure of modern Russian language: Interuniversity collection of scientific treatises, Moscow, 13-19.

Bulanin, L. (1986). Category of voice in modern Russian. Leningrad: Leningrad University Press.

Vinogradov, V. (1986). Russian Language: Grammatical doctrine on the word. Moscow: High school.

Vysotskaya, I. (2006). Syncretism in the part-of-speech system of the modern Russian language. Moscow: Moscow State Pedagogical University.

Gak, V. (1997). On pluralism in linguistic theories. NDVSh. Philological sciences, 6, 60-69.

Zernov, B. (1986). Interaction of parts of speech in English (static-dynamic aspect). Leningrad: Leningrad University Press.

Kalechits, E. (1990). Interaction of words in the part-of-speech system: (inter-categorial links). Sverdlovsk: Ural University Press.

Kim, O. (1978). Transposition at the part-of-speech level and the phenomenon of homonymy in the modern Russian language. Tashkent: Publishing House "Fan".

Belousov, V., Kovtunova, I., Kruchinina, I., Shvedova, N. (Ed.), \& Lopatin, V. (Ed.). (1989). Brief Russian grammar. Moscow: Russian language.

Kuznetsova, A. (1985). Quantitative criteria for identifying the center and periphery in the multidimensional indicative approach to the language description. Comparative Linguistics, 6, 16-25.

Kurilovich, E. (1962). Lexical derivation and syntactic derivation. In Linguistics Essays (pp. 57-70). Moscow.

Lukin, M. (1973). Transformation of parts of speech in modern Russian. Donetsk: Donetsk University Press.

Migirin, V. (1971). Essays on the Theory of transition processes. Beltsy.

Pavlov, V. (2001). Principle of the field in the grammatical study and the idea of contradiction. Research on linguistics: for the 70th anniversary of Corresponding Member of the Russian Academy of Sciences Alexander Vladimirovich Bondarko. Edited by Nedyalkov I.V. (pp. 1-6). St. Petersburg: St. Petersburg State University.

Rudelev, V. (1996). Dynamic theory of parts of speech of the Russian language. Tambov University Bulletin. "Humanities", Tambov, 85-86.

Evgenyeva, A. (Ed.). (1981-1984). Dictionary of Russian language: In 4 volumes, vol. 1. Academy of Sciences of the USSR. Institute of the Russian language; 2nd edition, revised and enlarged. Moscow: Russian language, 1981-1984.

Tenyer, L. (1988). Fundamentals of structural syntax. Moscow: Progress.

Shakhmatov, A. (1941). Syntax of the Russian language. 2nd edition. Leningrad: Uchpedgiz, Leningrad Department.

Shigurov, V. (1988). Transient phenomena in the field of parts of speech in a synchronous light. Saransk: Mordovia University Press.

Shigurov, V. (1993). Typology of using attributive forms of Russian verbs in negation of the action. Scientific Edition by Bulanin L.L. Saransk: Mordovia University Press.

Shigurov, V. (2003). Pronominalization as a type of stepped transposition of word forms into the parts of speech: (Materials for transpositional Russian grammar). Monograph. Saransk: Publishing House "Red October".

Shigurov, V. (2009a). Interjectivization as a type of stepped transposition of linguistic units into the parts of speech (Materials for transpositional Russian grammar). Moscow: Academia.

Shigurov, V. (2009b). Predicativization of adjectives and adverbs in the Russian language: essence, levels, limit. In B. Borisov, N. Goncharevich, A. Goryunov, et al., Humanitarian challenges of modern time: people and society: a monograph. Chapter 7 (pp. 165-197). Edited by Chernov S.S. Book 9. Novosibirsk: CRNS.

Shigurov, V., \& Shigurova, T. (2014). On some principles of description of the phenomena of transposition and syncretism in the part-of-speech theory. Basic Research, Moscow, 9 (part 2), 463-468. Retrieved June 11, 2015, from www.rae.ru/fs/?section=content\&op=show_article\&article_id=10004141.

Yartseva, V. (1968). Interaction of grammar and vocabulary in the language system. In Questions of the general theory of grammar (pp. 3-57). Moscow: Science.

Marchand, H. (1967). Expansion, transposition and derivation. La Linguistigue, 1.

Shigurov, V., \& Shigurova, T. (2015). Parenthetical-modal type of using finite verbs in the Russian language. $8 S$ ASS04. Asian Social Science, 91-CCSE. Canadian Center of Science and Education, 8(11) 292-298. 